\title{
A Cross-Sectional Study on the Health Status of Menopausal Women in Jharsuguda District, Odisha
}

\author{
Monika Satpathy \\ M.A, M.Phil in Home Science, Sambalpur University, Odisha
}

\begin{abstract}
Introduction: Menopause is a turning point in women's reproductive health. It's also a problematic periods as woman face a drastic change that is a transition from reproductive to non-reproductive stage which manifest different symptoms among women. Objective: This cross-sectional study aimed at evaluating various menopausal symptoms associated with the transitional periods and various demographic parameters like mean age at menarche, marriage, menopause etc among women aged between 40 and 60 years. Material and Methods: 100 women were selected (Jharsuguda district, Odisha) aged between 40 and 60 years, through simple random sampling method. Results: Mean age at menarche and menopause were $13.95 \pm 1.32$ and $43.94 \pm 5.03$ (mean \pm SD) respectively. Whereas mean age at marriage was found to be $20.58 \pm 3.7(m e a n \pm S D)$. The symptoms associated with menopause i.e somatic and urogenital problems were found to be higher in postmenopause in compared to pre and peri menopause where as psychological symptoms were higher in perimenopausal stage. Joint pain (68\%), hot flushes (67\%) and psychological symptoms like irritability (55\%), depressed mood (59\%) and anxiety (47\%).
\end{abstract}

Keywords: menstruation, menopause, menopausal transition, menopausal symptoms

\section{Introduction}

Menopause is a unique stage of female reproductive cycle, a transition from reproductive to non-reproductive stage. It is characterized by cessation of menstruation and implies loss of child bearing capacity and aging.[1] Menopause is defined as generally cessation of periods for 12 months or as time of cessation of ovarian function resulting in permanent amenorrhoea resulting from the loss of follicular activity of the of the ovaries.[2] It is a stage when the menstrual cycle stops for longer than 12 months and there is a drop in the levels of estrogens and progesterone, the two most important hormones in the female body.[3] The onset of this physiological development not only marks the end of women's reproductive function but also introduces them to a new phase of life. Although menopause is a universal phenomenon, there is a considerable variation among women regarding the age of attaining menopause and the manifestation of menopausal signs and symptoms. A number of studies have shown that biological (e.g., genetic, nutritional, and reproductive history); socio-cultural (e.g., educational, occupational, smoking habit and rural-urban residence); and lifestyle (e.g., smoking and use of tobacco and dietary habits) factors affect the age of menopause. During menopausal transition there is a lot of fluctuation in the hormone levels and thus women may experience many symptoms and conditions. This fluctuation varies from person to person. During the transition to menopause, women may experience vasomotor, urogenital, psychosomatic, and psychological symptoms, as well as sexual dysfunction.[4] There are also some serious physiological problems related to menopause as, osteoporosis and heart disease risk due to increases in weight, blood pressure and cholesterol levels.

\section{Material and Methods}

A cross-sectional study conducted from October 2014 to December 2014 covering urban areas of Jharsuguda district,Odisha. A total of 100 women aged between 40 and
60 years were selected as the study samples. The data were collected through house-to-house visits using a pre-tested, semi-structured proforma, based on Menopausal Rating Scale (MRS), which has been widely used in many epidemiological and clinical researches for investigation of menopausal symptoms. [5] Statistical Analysis: Data were entered and analyzed using Microsoft Office Excel 2007. Data presented as percentages for qualitative variable. For quantitative variable, mean and standard deviation were calculated.

\section{Results}

The study samples involved 100 women. Out of total women enrolled in the study, 97\% were married, while only $3 \%$ were single or widow or divorced. About $8 \%$ of women were illiterate, while $28 \%$ and $32 \%$ women had completed their primary and higher secondary schooling respectively. About $32 \%$ women were found to be graduate and above qualifications. Above $50 \%$ of the respondents have two numbers of parity. According to the menopausal transition $25 \%$ women were found to be in premenopausal stage while $28 \%$ and $47 \%$ women were in peri and post menopausal stage respectively.

Table 1: Demographic characteristics of the selected respondents

\begin{tabular}{|c|c|c|}
\hline Variables & $\mathrm{NO}$ & $\%$ \\
\hline \multicolumn{3}{|l|}{ Age of woman } \\
\hline $40-45$ & 39 & 39 \\
\hline $45-50$ & 36 & 36 \\
\hline $50-55$ & 17 & 17 \\
\hline$>55$ & 8 & 8 \\
\hline \multicolumn{3}{|l|}{ Educational status } \\
\hline Illiterate & 08 & 08 \\
\hline Less than $10^{\text {th }}$ & 28 & 28 \\
\hline $10^{\text {th }}$ to $12^{\text {th }}$ & 32 & 32 \\
\hline Graduation \& Above & 32 & 32 \\
\hline \multicolumn{3}{|l|}{ Merital status } \\
\hline Married & 97 & 97 \\
\hline
\end{tabular}


International Journal of Science and Research (IJSR)

ISSN (Online): 2319-7064

Index Copernicus Value (2013): 6.14 | Impact Factor (2015): 6.391

\begin{tabular}{|l|l|l|}
\hline Single/Widow/Divorced & 03 & 03 \\
\hline Parity & 13 & 13 \\
\hline 1 & 51 & 51 \\
\hline 2 & 20 & 20 \\
\hline $3-4$ & 16 & 16 \\
\hline 4 and above & 25 & 25 \\
\hline Menopausal Transition & 28 & 28 \\
\hline Premenopause & 47 & 47 \\
\hline Perimenopause & &
\end{tabular}

Table 2: Demographic parameters of respondents

\begin{tabular}{|c|c|}
\hline Variables & Mean (SD) \\
\hline Age at Menarche & $13.95(1.32)$ \\
\hline Age at Marriage & $20.58(3.7)$ \\
\hline Age at Menopause & $43.94(5.03)$ \\
\hline
\end{tabular}

In the present study the mean age at menarche is 13.95 , the mean age at marriage and menopause is 20.58 and 43.94 respectively. [Table-2]

As shown in Table 3, the occurrence of hot flushes and night sweats $(67 \%)$, joint pain $(68 \%)$ were very high, which were followed by depressed mood (59\%), irritability (55\%), sleep problem $(42 \%)$. (43\%) suffered from bladder problems where as vaginal dryness found to be $(26 \%)$. The table indicate that the psychological symptoms were found to be more in the transitional period compared to postmenopausal stage. Sex related problems found in less number among the study population that is only (17\%) and which is higher in premenopausal stage.

\section{Discussion}

The mean age at menarche in the present study was 13.95 years. The mean age at menarche in a study by Sarkar A et

al in 2014[6] and Shipra Gupta in Jamnagar in 2009[7] was 14.73 years which was higher than the present study. Sharma N. et al in 2006[8] in Jammu observed that mean age at menarche was 13.86 in two caste systems, namely Brahmins and Rajputs which was as per this study. The mean age at marriage in the present study was 20.58 years. This was relatively similar to 21 years in India (20.5 years in rural areas and 22.4 years in urban areas). The mean age at menopause observed in my study was 43.94 years. There is a wide range in mean age at menopause in Indian women from 40.32 to 48.84 yrs [9-18], and in developed countries from 48.29 to 51 yrs [19-22] have been suggested in the past studies. Mean age at menopause in Indian women is less in comparison to women from developed countries. Mean age at menopause in the present study corresponds with Singh \& Ahuja in 1980 [9] and Sharma \& Singh in 1980 [23]. Menopause is an important phase in women's life span. The present study evaluated the menopausal symptoms associated with the transitional phase (pre, peri and post menopause) and found that somatic and urogenital symptoms are higher in post menopausal women where as psychological symptoms were more prevalence in perimenopause. The most prevalent symptoms experienced by the women were joint pain $(68 \%)$, hot flushes and night sweats were observed $(67 \%)$ in menopausal women followed by psychological problems like irritability (55\%) and anxiety $(47 \%)$. Some women complained of bladder problems (43\%) and vaginal dryness (26\%), while a minority women had sexual problems. In studies by Sarkar et al 2014[6], Bansal et al 2010[24], Yahya and Rehan in 2002[25] prevalence of hot flushes and night sweats were $(59.3 \%),(47.3 \%),(32 \%)$ respectively which were lower than this study. The psychological symptoms like depression and irritability in the present study was corresponds with Sarkar et al 2014.[6] Most of the symptoms at menopause were related with decreased hormonal level.

Table 3: Symptoms associated with Menopausal Transition

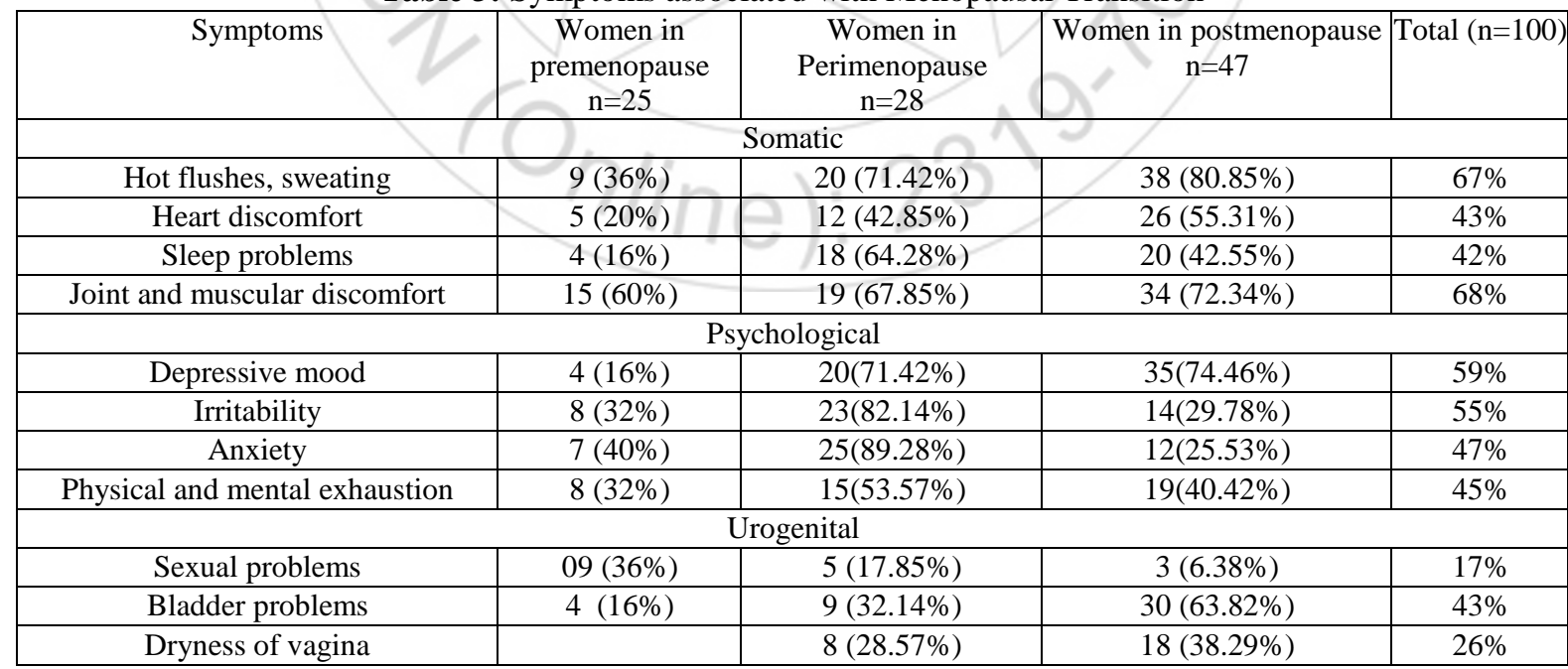

\section{Conclusion}

The number of postmenopausal women is increasing day by day. The hormonal changes during menopausal transition have important impact on the physiology, psychology and social life of women which lead many diseases and disabilities during post reproductive life. As the life expectancy is higher for females than males, they live onethird of their life in post menopausal phase. India is a country with diversity in ecology, economic status, social status, cultural norms, availability and accessibility of health care and education. Particularly the urban areas are exposed to modernization which effect their lifestyle, educational status, health status and medical services. The health 


\section{International Journal of Science and Research (IJSR) \\ ISSN (Online): 2319-7064 \\ Index Copernicus Value (2013): 6.14 | Impact Factor (2015): 6.391}

problems during menopause is due to the drastic hormonal changes during menopausal transition, so care and cooperation should be given to the menopausal women from their husband as well as from other family's member to easily tackle the transitional periods. Many people think that the symptoms of menopause are due to aging process, so do not need any treatment. There for proper guidance and education regarding menopause should be given to the women so that they can take proper remedy and treatment to handle the onset of menopause and a make a happy and worthy post menopausal life.

\section{Acknowledgement}

I express my deep sense of gratitude and respect to my guide Dr.Mrs Braja Kishori Mishra for her valuable guidance and sincere thanks to my husband Mr. Saradananda Mishra to inspire me for the preparation of this research paper.

\section{References}

[1] Bobak MI, Jenson MD. Maternity nursing. $1^{\text {st }}$ ed. Philadelphia: Mosby Year Book; 1997: 53-58.

[2] Shaw's Textbook of Gynaecology Menopause 2002:5667.

[3] World Health Organisation. Research on the menopause 1990s. Report of a WHO scientific group, WHO Technical Report Series 1996;886:1-107.

[4] Dasgupta D \& Ray S, Menopausal Problems Among Rural and Urban Women From Eastern India. Journal of Social, Behavioral and Health Sciences, 2009:1-24.

[5] HeinernannLAJ, Potthoff P., Schneider HP: International version of the Menopausal rating scale: Health Qual Life Outcomes 2003;1:28

[6] Sarkar Amrita,Pithadia Pradeep, Goswami Kakoli, Bhavsar Sudip, Makwana Naresh, Yadav sudha, Parmar Dipesh. A study on Health Profile of Post-menopausal Women in Jamnagar district, Gujurat, Journal of Research in Medical and Dental Science, 2014; 2(2)

[7] Shipra Gupta. A study of health profile of postmenopausal women in Jamnagar city, Gujarat. 2009. Dissertation submitted to Saurashtra/University. Unpublished thesis.

[8] Sharma N. et al. Age at menarche in two caste groups (Brahmins and Rajputs) from rural areas of Jammu. Anthropologist (2006). 8(1): 55-57

[9] Singh L., Ahuja S., Trend of menopause among the women of Punjab. Anthropologist. 1980;38:297-300

[10] Sengupta S., Gogoi G., Menarche and menopause among the Kaibarta women of Dibrugarh. Assam I Assam Sci Soc. 1993;35:113-19.

[11] Kulkarni VS, Joshi M. Reproductive life of two endogamous groups of Maharashtra. Man in Ind 1979;59:71-90

[12] Gosh AK, Kumari S. Effect of menarcheal age on fertility. J. Ind Anthrop Soc 1973;8:165-72.

[13] Baghla Nitika and Sharma Shubhagna Sharma. Onset age of menopause among women in Kangra district of Himachal Pradesh. The Anthropologist.2008;10(4):30507.

[14] Shah R., Kalgutkar S, Savardekar L, Chitlang S, Iddya $\mathrm{U}$, Balaiah D. Menopausal symptoms in urban Indian women. Menopausal symptoms in urban Indian women. Obs \& Gynae Today 2004; 11(10):667-70.

[15]Bagga A. Age and symptomatology of menopause: a case study. Obs\&Gynae Today 2004; 11(10):660-66.

[16] Kaw D., Khunna B., Vasishtha K. Factors influencing the age at natural menopause. J Obstet Gynecol Ind 1994:44:273-77.

[17] Sidhu Sharda, Avneet Kaur \& Sidhu Mandeep. Age at menopause in educated women of Amritsar (Punjab). J Hum Ecol 2005;18(1):49-51.

[18] Gogoi D. Menarche and menopause among women of an Ahom village of upper Assam. Dibrugarh University, Dibrugarh. Bull. Dept. Anthrop.1972.

[19] Kim YH, Ha EH, Shin SJ. A study on the menopausal symptoms and quality of life in middle aged women. TaehanKanhoHakhoe Chi 2003;33(5):601-8

[20] Mckinlay SM, Brambilla DJ, Possner JG. The normal menopause transition. Maturitas 1992; 14(2):103-05.

[21] Oldenhave A., Netelenbos C. Pathogenesis of climacteric complaints: ready for the changes. Lancet 1994;343(8898):649-53.

[22] Sudha Sharma,Vishal Tandon, Anil Mahajan. Menopausal symptoms in urban women.JK Science.2007;9(1):13-17.

[23] Sharma N , Singh R, Age at menarche and menopause of Brahmins and choudary females of kangra valley. Proceedings of international symposium on human growth , Patiala- India.1980.

[24] Bansal Priya, Chaudhary Anurag, Soni R.K ,Kaushal Pushapindr, Menopausal problems among rural middle aged women of Punjab,International Journal of Research in Health Sciences, Oct-Dec 2013;1(3): 103

[25] Yahya, S., Rehan, N.: Age pattern and symptoms of menopause among rural women of Lahore. J.AyubMed.Coll. Abbottabad. 2002; 14:9-12

\section{Author Profile}

Monika Satpathy, M.A, M.Phil, Department of Home Science, Sambalpur, University, Odisha, India 